\title{
EAl Endorsed Transactions

\section{Eurasian Wolves-Cuckoo Search Optimizer for Localization of Mobile Sensor Nodes using Single Beacon Node in WSN}

\author{
Ravi Sharma ${ }^{1, *}$ and Shiva Prakash ${ }^{2}$ \\ ${ }^{1}$ Department of Computer Science and Engineering, Madan Mohan Malaviya University of Technology - Gorakhpur, India \\ ${ }^{2}$ Department of Information Technology and Computer Application, Madan Mohan Malaviya University of Technology - \\ Gorakhpur, India.
}

\begin{abstract}
Wireless Sensor Networks (WSNs) is a widely used technology for remote area monitoring in collaboration with the Internet of Things (IoT). The fundamental research challenge of mobile sensor nodes for the WSN community is localization. The sensor node localization of the WSN is related to the NP-hard problem, and because of this, determining the actual coordinate of the sensor node is quite complex. The computational intelligence approach is assisted in obtaining an optimal solution to the given NP-hard problem. Most researchers today are more concerned about three beacon-based localization approaches, but the fewest researchers are concerned about two or single beacon-based localization approaches. This paper provides a single beacon-based localization approach using the hybrid approach of the Eurasian Wolves Optimizer (EWO) and the Cuckoo Search Optimizer (CSO) algorithm called the EW-CSO computational intelligence algorithm for randomly deployed mobile sensor nodes. The simulation results of the computational intelligence algorithms show that the proposed work using EW-CSO performs better in terms of mean localization error, computational cost, and number of localized nodes from the EWO and EW- Particle Swarm Optimization (EW-PSO) algorithms. It also reduced the line of sight problem for mobile sensor nodes with efficient use of network resources.
\end{abstract}

Keywords: Wireless Sensor Network, Mobile Sensor Nodes, Beacon Node, Computational Intelligence, Localization Error, Computational Cost

Received on 08 April 2020, accepted on 04 May 2020, published on 13 May 2020

Copyright (c) 2020 Ravi Sharma et al., licensed to EAI. This is an open access article distributed under the terms of the Creative Commons Attribution licence (http://creativecommons.org/licenses/by/3.0/), which permits unlimited use, distribution and reproduction in any medium so long as the original work is properly cited.

doi: 10.4108/eai.13-7-2018.164553

\section{Introduction}

Today is the era of technological automation [1], where systems are designed with the help of global networks (Internet) in such a way that human intervention is minimized. Researchers worked with the IoT system to meet all the requirements of technical automation [2] [3] [4]. These types of systems consume a lot of data to solve real-time challenges. A large amount of realistic data can be collected using only WSNs [5]. Researchers are more concerned about the design of Wireless Sensor Networks and Internet of Things (WSN-IoT) system integration [6]. Real-time data are collected by sensor nodes under the umbrella of a Wireless
Sensor Network (WSN). The collected data of the sensor nodes have no meaning until the WSN knows its actual state. Thus, the localization of sensor nodes becomes an essential challenge for WSNs [7].

The localization algorithm is classified into two parts such as range-based and range-free-based localization approaches [8] [9]. Range-based localization approaches [10] are designs based on distance or angle calculation between nodes and while range-free-based localization approaches [11] use hop count between sensor nodes to estimate the coordination of sensor nodes. The range-based localization approaches are the Received Signal Strength Indicator (RSSI) [12], Time of Arrival (ToA) [13], Angle of Arrival (AoA) [14] and Time Difference of Arrival (TDoA) [15]. Range-free-based

*Corresponding author. ravi.cs.0904@gmail.com 
Table 1. Taxonomy of beacon-based localization approaches for sensor nodes in WSN

\begin{tabular}{|c|c|c|c|}
\hline Parameters & $\begin{array}{l}\text { Single } \\
\text { beacon- } \\
\text { based } \\
\text { localization } \\
\text { approach } \\
\text { [22] }\end{array}$ & $\begin{array}{l}\text { Two } \\
\text { beacons- } \\
\text { based } \\
\text { localization } \\
\text { approach } \\
{[20][21]}\end{array}$ & $\begin{array}{l}\text { Three } \\
\text { beacons- } \\
\text { based } \\
\text { localization } \\
\text { approach } \\
\text { [19] }\end{array}$ \\
\hline $\begin{array}{l}\text { Available one } \\
\text { beacon node }\end{array}$ & Work & Fail & Fail \\
\hline $\begin{array}{l}\text { Available two } \\
\text { beacon nodes }\end{array}$ & Work & Work & Fail \\
\hline $\begin{array}{c}\text { Available } \\
\text { three beacon } \\
\text { node }\end{array}$ & Work & Work & Work \\
\hline $\begin{array}{c}\text { Dense } \\
\text { network } \\
\text { deployment }\end{array}$ & Low & Moderate & High \\
\hline $\begin{array}{c}\text { Computational } \\
\text { cost }\end{array}$ & High & Moderate & Low \\
\hline $\begin{array}{c}\text { Mean location } \\
\text { error }\end{array}$ & Low & Moderate & High \\
\hline $\begin{array}{c}\text { Number of } \\
\text { localized } \\
\text { nodes }\end{array}$ & High & Moderate & Low \\
\hline
\end{tabular}

localization approaches are Distance Vector-Hop (DV-Hop) [16], Ad-Hoc Positioning System (APS) [17], and MultiDimensional Scaling (MDS) [18].

In range-based localization approaches, beacon nodes information is required to estimate the coordination of sensor nodes. Beacon nodes are nodes whose coordinate information is known in the system. The localization of sensor nodes requires at least three number of beacon nodes [19]. The cost of beacon nodes in the system is higher than the deployment of sensor nodes due to the additional cost of a Global Positioning System (GPS) equipped with beacon nodes. Localization of two beacons [20] [21] and single beacon nodes [22] occurs in WSNs to reduce the hardware cost of beacon nodes in the system.

Most researchers are concerned about three beacon-based localization approaches compared to two and single based localization systems. Three beacon-based approaches using computational intelligence algorithms [23] present an enormous amount of WSN operational research domains for the localization of sensor nodes. A variety of beacon nodesbased localization algorithms, such as three beacons, two beacons, and single beacon-based localization approaches. Three beacon-based localization approaches consisting of at least three beacon nodes, two beacon-based localization approaches consisting of at least two beacon nodes, and a single beacon-based localization approach consisting of at least one beacon node and two virtual nodes is needed. Single, two, three based localization approaches in WSNs have been compared with network performance standards, as shown in Table 1, and definitions are presented below.
- Number of available beacon nodes:

The total number of beacon nodes is required to complete the localization of the sensor node.

- Density of the network:

The total number of sensor nodes is deployed to provide complete coverage of the target area.

- Computational cost:

The total time required to complete the process of localization of the sensor nodes deployed in the target area. Generally, it is measured in seconds time units.

- Mean location error:

In the localization process of the sensor nodes, the location error calculated as the average difference between the actual location and the estimated location.

- Number of localized nodes:

The total number of localized sensor nodes after the completion of the localization process in terms of beacon nodes.

\section{Background}

This sub-section of the introduction section describes how well-known computational intelligence algorithms work. Computational intelligence algorithms such as EWO, CSO, and PSO are as follows:

Eurasian Wolves Optimizer (EWO): Mirjalili et al. [24] proposed an EWO algorithm for eurasian wolves' inspired leadership quality. It is a swarm computational intelligence algorithm similar to Particle Swarm Optimization (PSO), Ant Colony Optimization (ABC) algorithm. However, it is far superior to other swarm optimization algorithms. This mimics the lead pecking order and the relationship of wolves, as shown in Figure 1. The social pecking order is simulated by classifying the population of search agents based on their fitness:

- Level 1 (Alpha):

This is the leader who is male or female. Alpha is mostly responsible for decision making (such as hunting, sleeping places, etc.). Others accept alpha by putting their tails down.

- Level 2 (Beta):

Betas are subordinate wolves who help alpha in making decisions. Beta is an advisor to alpha of this pack. They consider the best candidate to be an alpha when the alpha dies or becomes too old. Beta ensures alpha's orders are followed and it also provides them with feedback.

- $\quad$ Level 3 (Delta):

Deltas are also subordinate wolves. Delta wolves dominate Omega and report to alpha and beta. The delta can be classified as follows:

- Scouts: Responsible for visualizing boundaries.

- Sentinels: Responsible for protecting the pack

- Elders: Which were sometimes alpha or beta.

○ Hunters: Supports alpha and beta in hunting. 


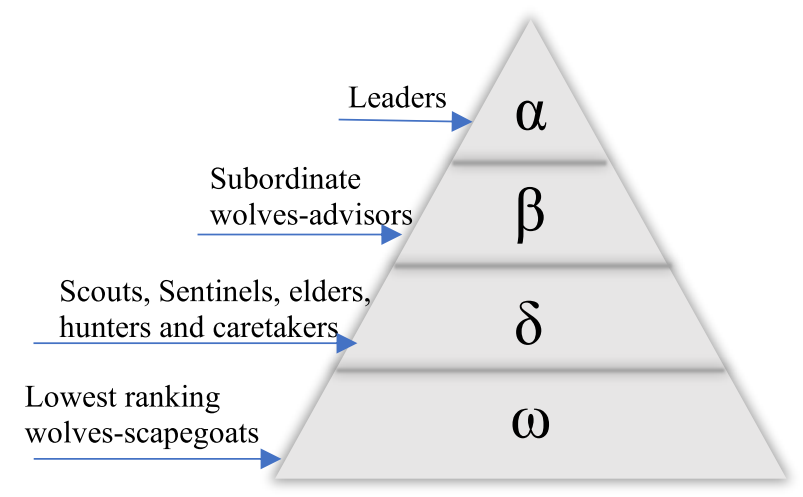

Figure 1. Grey Wolves Optimizer Social Hierarchy

- Caretakers: Responsible for caring for sick, weak and injured wolves

- $\quad$ Level 4 (Omega):

It is like a sacrificial goat in a pack.

EWO Search Process: The model demonstrated mimic hunting behavior of eurasian wolves to use three stages, searching, circling, and attacking prey. The first two stages are given to the exploration process and the last one presents the exploitation process. EWO saves the first three best solutions and is obliged to modify their location according to the best position of the rest of the search agents.

- Searching (exploration): Finding the prey.

- Encircling (exploration): During the hunting process, they first surround the prey.

- Attacking (exploitation): Usually guided by alpha, beta and delta can play a role according to the situation.

Searching (Exploration): Eurasian wolves typically detect the search process according to alpha, beta, and delta positions. They distributed themselves from one another to exploit to locate prey and attack prey. The EWO algorithm uses the A constraint, in which $\mathrm{A}$ is a random value, and its value is greater than 1 or less than -1 . The search agents may diverge from the prey when $|\mathrm{A}|>1$, and they force to diverge for finding a better one.

Encircling (Exploration): Eurasian wolves encircling the prey before hunting. The encircling behavior calculated by using mathematical equations (1) and (2) are as follows:

$$
\begin{aligned}
& \vec{D}=\left|\vec{C} \cdot \overrightarrow{X_{p}}(t)-\vec{X}(t)\right| \\
& \vec{X}(t+1)=\overrightarrow{X_{p}}(t)-\vec{A} \cdot \vec{D}
\end{aligned}
$$

Where t presents the current iteration, $\vec{A}$ and $\vec{C}$ are coefficient vectors, $\overrightarrow{X_{p}}$ is the prey position vector, and $\vec{X}$ presents the eurasian wolves position vector.

The vector $\vec{A}$ and $\vec{C}$ computed using equations (3) and (4) as follows:

$$
\vec{A}=2 \cdot \vec{a} \cdot \overrightarrow{r_{1}}-\vec{a}
$$

$$
\vec{C}=2 \cdot \overrightarrow{r_{2}}
$$

Where $\vec{a}$ is linearly reduced from 2 to 0 in the iterations, and $r_{1}, r_{2}$ are random vectors $[0,1]$.

Attacking Prey (Exploitation): Eurasian wolves end the hunt when the prey stops moving. In the EWO algorithm, when $|\mathrm{A}|<1$, then the wolves attack the prey.

Cuckoo Search Optimizer (CSO): Yang et al. [25] have developed a nature-inspired computational intelligence algorithm from cuckoo birds. Cuckoo birds are laying their eggs in another host bird's nest.

The cuckoo search algorithm has three ideal rules:

- At a certain time, each cuckoo bird lays its eggs in a randomly chosen nest.

- The best nesting takes the high quality of eggs to the next levels.

- The probability of a stranger egg between 0 and 1 is calculated from the number of available hosts.

Particle Swarm Optimization (PSO): Kennedy et al. [26] have developed a nature-inspired algorithm from the social behavior of bird flocking or fish schooling. PSO uses Artificial Intelligence (AI) to find optimal solutions to extremely difficult problems. The hypotheses are plotted in the search space along with the initial velocity of random particles. The value of the particles is moving towards the search space by evaluating the fitness value after each iteration. Each particle is updated with two best values, i.e., $p_{\text {best }}$ and $g_{\text {best }}$. Each particle is the current position, and the velocity is modified below equations 3 and 4 .

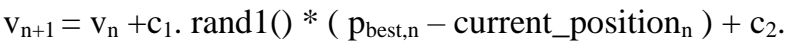

$$
\begin{aligned}
& \operatorname{rand} 2() *\left(\mathrm{~g}_{\text {best, }} \text { - current_position } \mathrm{n}\right) \\
& \text { current_position[n+1] = current_position[n]+v[n+1] }
\end{aligned}
$$

where current_position[n+1] is a particle position at $(n+1)$ iteration, current_position[n] is a position at $n$ iteration, $v_{n+1}$ is a velocity of particle at $(n+1)$ iteration, $v_{n}$ is a velocity of particle at (n) iteration, $\mathrm{c}_{1}$ is a $\mathrm{g}_{\text {best }}$ acceleration factor, $\mathrm{c}_{2}$ is a pest acceleration factor, rand1() and rand2() is a random number $[0,1], g_{\text {best }}$ is a swarm position, pest is a particle position.

In this paper, the range-based localization approach was used to design a single beacon-based localization algorithm, in which EW-CSO was formed for the localization of a randomly deployed mobile sensor node using the EWO and CSO computational intelligence algorithms. After a lot of advanced search in the research domain, results come that the EWO algorithm and its hybrid algorithm are still not used with a single beacon-based localization approach. The main contribution of this paper is:

- To propose the implementation of single beacon-based localization approaches using the EWO algorithm. 
- EWO with the CSO algorithm is used for the implementation of a single beacon-based localization approach.

- EWO with the PSO algorithm is used for the implementation of a single beacon-based localization approach.

The advantage of the proposed work implementation to provide more accurate and less computation time to localize the mobile sensor nodes. Simulation results of the proposed works in which the EW-CSO algorithm performs better in the mean localization error, computation cost, and number of localized nodes compared with the EWO and EW-PSO algorithms in a single beacon-based localization approach. The computations of EWO and EW-PSO are almost equal in terms of cost when the deployment of mobile sensor nodes with high density in the WSN.

This paper is structured as follows: section two presents a literature survey of respected existing works in the field of beacon-based mobile sensor node localization, section three provides the proposed approach model, flowchart and algorithm, section four provides the proposed work evaluation among them in terms of mean localization error, computation cost, number of localized nodes, and section five present the conclusions of the designed paperwork.

\section{Literature Survey}

This section provides a critical analysis of the latest research works available in the field of beacon-based localization in WSNs using computational algorithms. The literature survey of the existing work is further classified into two-part; the first part consists of a single beacon-based localization approach and miscellaneous beacon-based localization approaches using computational intelligence algorithms. Miscellaneous beacon-based localization consists of more than single beacon nodes used to localize mobile sensor nodes.

\section{Single beacon-based localization approaches}

Singh et al. [22] proposed a single anchor node-based localization of sensor nodes in WSN with the support of Computational Intelligence (CI) algorithms. The CI algorithm reduces hardware requirements for accurate localization of sensor nodes in an application. Only one anchor node is using virtual nodes for precise localization of mobile sensor nodes within its range. Mobile sensor nodes estimate their location, once mobile sensor nodes fall within the scope of two of the six virtual nodes surrounding the anchor nodes. The results of this work experiment showed effective results in terms of the number of mobile sensor nodes localization accuracy and scalability. The problem of line of sight is encountered in harsh environments, that is, minimized by the projection of virtual anchor nodes.

A novel 3D node localization algorithm proposed by Singh et al. [27] with the help of Computational Intelligence (CI) algorithms. CI algorithms such as PSO , H-Best PSO (HPSO), Firefly Algorithm (FA), and Biography-Based Optimization (BBO) are used to estimate the optimal coordinate value of a moving target node using a single reference node/ anchor node in WSN. Each sensor node has heterogeneous properties according to its battery status, and the Degree of Irregularity (DoI) of the radiation pattern is 0.1 . The single-node range-based sensor node used three virtual nodes to estimate the 3D position of the mobile target node. Umbrella projection is used to find the 3D projection of the target of the moving node. HPSO and PSO based algorithms are much better performed for the 3D based positioning of target mobile nodes than BBO and FA algorithms.

A novel idea of sensor nodes localization based on moving single anchor node is proposed by Singh et al. [28] using CI algorithms such as PSO and H-best PSO (H-PSO). The Hilbert trajectory follows the mobile anchor node. The only single anchor node used as a reference node to localize the entire sensor node in the WSN. The proposed algorithm minimizes the Line of Sight (LOS) problem with the help of virtual anchor nodes. The H-PSO algorithm has much better accuracy and convergence rate than the PSO algorithm.

Two-way planning models using mobile anchor nodes in WSNs localize sensor nodes, and they are linear mesh scanning and triangular mesh scanning. The work objective proposed by Kaur et al. [29] to provide a model for unused nodes localization with high accuracy and convergence rate in all types of scenarios. The single mobile anchor node uniformly finds different reference points to locate the unsettled sensor nodes in the network area. The proposed work is simulated and evaluated compared to traditional works, and its results are shown in terms of high accuracy and coverage.

Singh et al. [30] provided review chapter work in the field of CI techniques for the localization of sensor nodes in static and dynamic WSNs. The latest emerging work in the area of sensor nodes localization in WSNs is presented in this paper. Various connectivity, range-based, mobility-based localization techniques for sensor nodes were discussed. For optimization, these CI algorithms, such as PSO, BBO, FA, estimate coordination of sensor nodes with Genetic Algorithm (GA), and their results in various scenarios are discussed.

\section{Miscellaneous beacon-based localization approaches}

Tuba et al. [31] proposed two-stage sensor node localization using a firefly algorithm. In the WSN, the RSSI (Received Signal Strength Signal) propagation model is used to estimate the distance between the anchor nodes and the semi anchor nodes. The proposed algorithm for the localization of the sensor node follows a two-part: first, four anchor nodes are placed at the corners of the target area coverage and secondly the estimation of the optimal distance using distance calculation. The future direction of this work for an optimal approach for localization of sensors with firefly algorithm modification and adjustment.

Monarch butterfly optimization algorithm used by Strumberger et al. [32] to solve the NP-hard problem of WSN localization. The novel Monarch Butterfly Swarm intelligence approach uses multi-phase localization for sensor nodes. Monarch butterfly optimization is implemented and 
Table 2. Taxonomy of single beacon-based localization approaches using computational intelligence algorithms for sensor nodes in WSNs

\begin{tabular}{|c|c|c|c|c|c|c|}
\hline Authors & $\begin{array}{l}\text { Year } \\
\text { of } \\
\text { Publi- } \\
\text { cation }\end{array}$ & $\begin{array}{l}\text { Design } \\
\text { approach }\end{array}$ & Techniques use & $\begin{array}{l}\text { Compared } \\
\text { approaches }\end{array}$ & Target parameters & $\begin{array}{c}\text { Simulation } \\
\text { Tool }\end{array}$ \\
\hline $\begin{array}{l}\text { Singh et } \\
\text { al. [22] }\end{array}$ & 2018 & $\begin{array}{l}\text { A single anchor- } \\
\text { based moving } \\
\text { target sensor } \\
\text { node localization } \\
\text { using } \mathrm{Cl}\end{array}$ & $\begin{array}{c}\text { Projection of } \\
\text { virtual anchor } \\
\text { nodes, } \\
\text { Bio-inspired } \\
\text { localization }\end{array}$ & $\begin{array}{l}\text { HPSO, } \\
\text { BBO, } \\
\text { FA }\end{array}$ & $\begin{array}{l}\text { Accurate location, } \\
\text { Fast convergence, } \\
\text { Non-line of sight }\end{array}$ & MatLab \\
\hline $\begin{array}{l}\text { Singh et } \\
\text { al. [27] }\end{array}$ & 2017 & $\begin{array}{l}\text { A single anchor- } \\
\text { based moving } \\
\text { target sensor } \\
\text { nodes 3D } \\
\text { localization in } \\
\text { WSN } \\
\end{array}$ & $\begin{array}{l}\text { Bio-inspired } \\
\text { localization }\end{array}$ & $\begin{array}{c}\text { PSO, } \\
\text { HPSO, } \\
\text { BBO, } \\
\text { FA }\end{array}$ & $\begin{array}{c}\text { Mean localization } \\
\text { error, } \\
\text { Highest localization } \\
\text { error, } \\
\text { Lowest localization } \\
\text { error } \\
\end{array}$ & MatLab \\
\hline $\begin{array}{l}\text { Singh et } \\
\text { al. [28] }\end{array}$ & 2018 & $\begin{array}{l}\text { A single mobile } \\
\text { anchor node- } \\
\text { based optimized } \\
\text { localization in } \\
\text { WSN }\end{array}$ & $\begin{array}{l}\text { Bio-inspired } \\
\text { localization }\end{array}$ & $\begin{array}{l}\text { PSO, } \\
\text { HPSO }\end{array}$ & $\begin{array}{c}\text { Average } \\
\text { localization error, } \\
\text { Convergence time }\end{array}$ & MatLab \\
\hline $\begin{array}{l}\text { Kaur et } \\
\text { al. [29] }\end{array}$ & 2019 & $\begin{array}{l}\text { The mesh path } \\
\text { planning } \\
\text { algorithms- } \\
\text { based } \\
\text { localization } \\
\text { using a single } \\
\text { mobile anchor } \\
\text { node }\end{array}$ & $\begin{array}{l}\text { Linear mesh } \\
\text { scanning, } \\
\text { Triangular mesh } \\
\text { scanning }\end{array}$ & $\begin{array}{c}\text { DV-hop, } \\
\text { Ahmad et al. } \\
{[38]}\end{array}$ & $\begin{array}{l}\text { Localization error } \\
\text { coverage }\end{array}$ & MatLab \\
\hline $\begin{array}{l}\text { Singh et } \\
\text { al. [30] }\end{array}$ & 2019 & $\begin{array}{l}\text { Review work for } \\
\text { computational } \\
\text { intelligence } \\
\text { algorithms for } \\
\text { static and } \\
\text { dynamic WSNs }\end{array}$ & $\begin{array}{l}\text { Bio-inspired } \\
\text { localization }\end{array}$ & $\begin{array}{c}\text { GA, } \\
\text { PSO, } \\
\text { BBO, } \\
\text { FA }\end{array}$ & $\begin{array}{c}\text { Total overhead } \\
\text { communication, } \\
\text { total consumption } \\
\text { power, } \\
\text { total time } \\
\text { convergence, } \\
\text { algorithmic } \\
\text { complexity }\end{array}$ & MatLab \\
\hline
\end{tabular}

tested on several problem examples that are found in the literature. Experimental result analysis of the proposed work from other approaches has been successfully presented and has shown considerable potential in terms of solving the NPhard problem of WSN localization.

A location-aware mobile anchor (MA) uses path planning to optimize mobile nodes. The work of MA to traverse into the target region of interest to minimize localization error and maximize localization of the successful node. Alomari et al. [33] proposed two novel dynamic movement approaches that provide the obstacle avoidance path planning for mobile node localization in WSN. Movement planning of mobile nodes designed based on two swarm intelligence-based algorithms, i.e., GWO and Whale Optimization Algorithm (WOA). Comparing this proposed approach to the snake-like and zcurve models, it has shown remarkable results in terms of localization ratio, localization accuracy, and computation time.

An Elephant Herring Optimization (EHO) algorithm is adopted by Strumberger et al. [34] to solve localization problems in WSN. New metaheuristic computational intelligence approach dealing with NP-hard problems to achieve a near to target coordination value. The purpose of this approach is for the localization of randomly deployed sensor nodes in the monitoring area. The implementation of EHO for node localization in a WSN and results in efficient metaheuristic approaches to deal with sensor nodes localization. The work presents a future direction of the EHO algorithm that can apply to efficient solutions to the superset problem of node localization, i.e., the coverage problem in WSNs. 
Table 3. Taxonomy of miscellaneous beacon-based localization approaches using computational intelligence algorithms sensor nodes in WSNs

\begin{tabular}{|c|c|c|c|c|c|c|}
\hline Authors & $\begin{array}{l}\text { Year } \\
\text { of } \\
\text { Public } \\
\text { ation }\end{array}$ & $\begin{array}{l}\text { Design } \\
\text { approach }\end{array}$ & Techniques use & $\begin{array}{l}\text { Compared } \\
\text { approaches }\end{array}$ & Target parameters & $\begin{array}{l}\text { Simulation } \\
\text { Tool }\end{array}$ \\
\hline $\begin{array}{l}\text { Tuba et } \\
\text { al. [31] }\end{array}$ & 2018 & $\begin{array}{l}\text { FA-based } \\
\text { sensor nodes } \\
\text { localization in } \\
\text { two-stage }\end{array}$ & $\begin{array}{l}\text { Semi-mobile } \\
\text { nodes, } \\
\text { Firefly } \\
\text { optimization } \\
\text { algorithm } \\
\end{array}$ & $\begin{array}{c}\text { 3D } \\
\text { Localization, } \\
\text { PSO Algorithm, } \\
\text { (TLP), } \\
\text { BA }\end{array}$ & $\begin{array}{l}\text { Improve } \\
\text { localization } \\
\text { accuracy }\end{array}$ & MatLab \\
\hline $\begin{array}{l}\text { Strumbe } \\
\text { rger et } \\
\text { al. [32] }\end{array}$ & 2018 & $\begin{array}{l}\text { Sensor nodes } \\
\text { localization } \\
\text { using Monarch } \\
\text { butterfly } \\
\text { optimization } \\
\text { algorithm in } \\
\text { WSN }\end{array}$ & $\begin{array}{l}\text { Monarch butterfly } \\
\text { optimization }\end{array}$ & $\begin{array}{c}\text { PSO, } \\
\text { MPSO, } \\
\text { ABC, } \\
\text { MSABC, } \\
\text { MBO }\end{array}$ & $\begin{array}{c}2.5 \% \text { of anchor } \\
\text { nodes with }(20 \mathrm{~m} \\
50 \mathrm{~m}), \\
10 \% \text { of anchor } \\
\text { nodes with } 50 \mathrm{~m}\end{array}$ & MatLab \\
\hline $\begin{array}{l}\text { Alomari } \\
\text { et al. } \\
\text { [33] }\end{array}$ & 2018 & $\begin{array}{l}\text { To obstacle } \\
\text { avoidance for } \\
\text { mobile anchor } \\
\text { nodes using } \\
\text { swarm } \\
\text { intelligence } \\
\text { optimization } \\
\text { algorithms }\end{array}$ & $\begin{array}{l}\text { EWO, } \\
\text { WOA }\end{array}$ & $\begin{array}{l}\text { Snake-like, } \\
\text { Z-curves }\end{array}$ & $\begin{array}{l}\text { Localization ratio, } \\
\text { Localization error, } \\
\text { Computation time }\end{array}$ & MatLab \\
\hline $\begin{array}{l}\text { Strumbe } \\
\text { rger et } \\
\text { al. [34] }\end{array}$ & 2018 & $\begin{array}{c}\text { WSN } \\
\text { localization } \\
\text { using EHO } \\
\text { algorithm }\end{array}$ & EHO algorithm & $\begin{array}{c}\text { PSO, } \\
\text { Multi step PSO, } \\
\text { ABC, } \\
\text { Multi step ABC }\end{array}$ & Mean squared error & $\begin{array}{l}\text { Experim- } \\
\text { ental } \\
\text { setup }\end{array}$ \\
\hline $\begin{array}{l}\text { Rajaku } \\
\text { mar et } \\
\text { al. [35] }\end{array}$ & 2017 & $\begin{array}{l}\text { EWO algorithm } \\
\text { for node } \\
\text { localization } \\
\text { problem in } \\
\text { WSNs }\end{array}$ & EWO & $\begin{array}{l}\text { PSO, } \\
\text { MBA }\end{array}$ & $\begin{array}{c}\text { Computation time, } \\
\text { minimum } \\
\text { localization error, } \\
\text { localized nodes }\end{array}$ & MatLab \\
\hline $\begin{array}{l}\text { Strumbe } \\
\text { rger et } \\
\text { al. [36] }\end{array}$ & 2019 & $\begin{array}{c}\text { A node } \\
\text { localization in } \\
\text { WSNs using } \\
\text { EHO and tree } \\
\text { growth algorithm }\end{array}$ & $\begin{array}{l}\text { EHO algorithm, } \\
\text { tree growth } \\
\text { algorithm }\end{array}$ & $\begin{array}{l}\text { Iterative best } \\
\text { performance } \\
\text { algorithm, } \\
\text { taboo search, } \\
\text { largest } \\
\text { absolute } \\
\text { difference } \\
\text { algorithm, } \\
\text { weighted } \\
\text { superposition } \\
\text { attraction }\end{array}$ & $\begin{array}{l}\text { Localized number } \\
\text { nodes, } \\
\text { localization error, } \\
\text { execution time }\end{array}$ & -- \\
\hline $\begin{array}{l}\text { Tan et } \\
\text { al. [37] }\end{array}$ & 2019 & $\begin{array}{l}\text { A sensor node } \\
\text { localization } \\
\text { using distance } \\
\text { mapping } \\
\text { algorithm }\end{array}$ & $\begin{array}{c}\text { DMA, } \\
\text { optimized linear } \\
\text { transforming } \\
\text { function, } \\
\text { GA }\end{array}$ & $\begin{array}{l}\text { DV hop, } \\
\text { MDS map }\end{array}$ & $\begin{array}{l}\text { Localization error, } \\
\text { Total consumption } \\
\text { of energy }\end{array}$ & $\begin{array}{l}\text { Network } \\
\text { Simulator }\end{array}$ \\
\hline
\end{tabular}

Rajkumar et al. [35] proposed work by incorporating the Grey Wolf Optimization (GWO) algorithm to detect the accurate geographic location of unknown sensor nodes with the help of anchor nodes in WSNs. The GWO algorithm mimics the social behavior of a grey wolf leadership to attack targets. The suggested work is implemented using the MatLab tool for randomly deployed sensor nodes in the target region. Parameters such as computation time, localized node percentage, minimum number of error measures for analysis of GWO's ability, 
and other types of metaturistic algorithms. The result of faster convergence and success rate of the GWO algorithm is better than other PSO and other metaheuristics algorithms like the Modified BAT algorithm (MBA).

An improved version of metaheuristic algorithms, such as the tree development algorithm and the EHO algorithm, is proposed by Strumberger et al. [36] to solve the localization problem of WSNs. The improvement of the proposed algorithm is analyzed by varying the size of the sensor network from 25 to 150 target nodes. The state of the art of some swarm intelligence algorithms is tested in comparison to the proposed algorithm. Simulation results indicate that the proposed algorithm achieves very efficient results in terms of accurate location estimation of the coordinate of the unknown sensor node.

A distance mapping algorithm (DMA) is proposed by Tan et al. [37] to overcome the node localization problem in WSN. To detect node position with high accuracy using the estimation matrix, distance matrix, and optimized linear transformation function. GA is employed for the optimal detection coordinate value of nodes during the calculation of the proposed algorithm. The node localization approach was simulated using three anchor nodes by the researcher in the laboratory. The results of the proposed algorithm perform well in terms of localization accuracy and energy consumption other than the localization algorithm.

Current important works of literature in the field of beaconbased localization WSNs based on various parameters such as authors' publication, design approach, technique use, comparison approach, target parameters, and simulation tools. Table 2 and Table 3 show the taxonomy of a single and miscellaneous beacon-based localization approach using computational intelligence algorithms.

After a critical analysis of the presented literature works, the localization of sensor nodes became a vital challenge of WSN. Due to the unpredictable behavior of the sensor node, the localization approach became an NP-hard problem. To solve these various computational intelligence algorithms, localization approaches are used to estimate the optimal solution. In section, the presented literature survey paper concern about the three-beacon based location, and they are trying to improve the measured position of sensor nodes using computational intelligence algorithms such as PSO, BBO, FA, Artificial Bee Colony (ABC), Bat Algorithm (BA), EWO, etc. EWO is the smartest computational intelligence optimization algorithm compared to other computational intelligence algorithms. But still, EWO, EW-CSO, and EW-PSO are not used in single beacon-based localization approaches. However, this paper is trying to apply the EW-CSO algorithm to a single node-based localization approach and provides simulation analysis of the results based on the mean localization error, computational time, and number of local nodes.

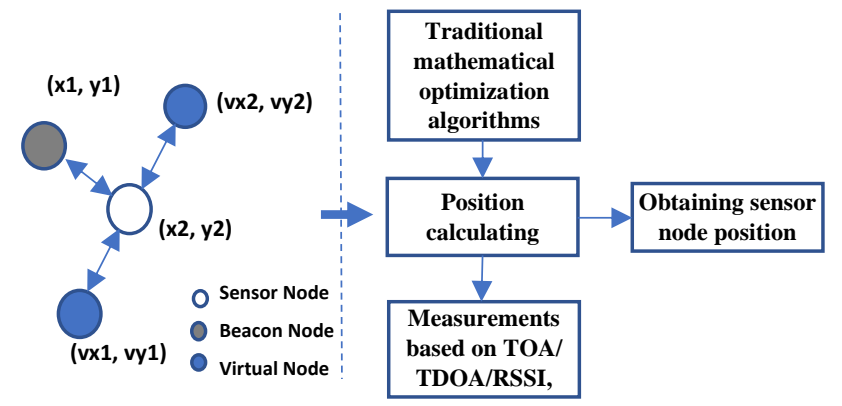

Figure 2. Single beacon-based mobile sensor nodes localization using traditional mathematical optimization algorithm in WSN

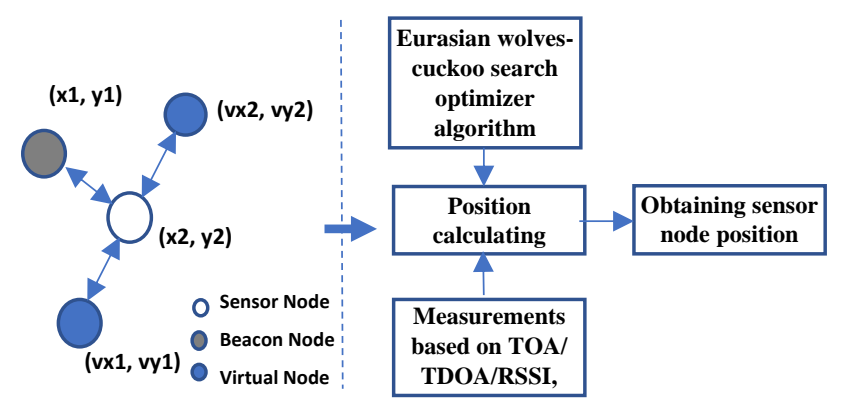

Figure 3. Single beacon-based mobile sensor nodes localization using EW-CSO Algorithm in WSN

\section{Localization Problem Formulation}

The proposed work design for the formation of mobile sensor node position estimation challenges in a single beacon-based localization approach using computational intelligence algorithms is presented. The localization problem formulation is further classified into a subsection of the proposed model, the proposed flow chart, and the proposed algorithm.

\section{Proposed Model}

The proposed model was built with the components of beacon sensor node $(\mathrm{x} 1, \mathrm{y} 1)$, sensor node $(\mathrm{x} 1, \mathrm{y} 2)$, virtual nodes ((vx1, vy1), (vx2, vy2)), computational intelligence algorithms (EW-CSO) and measuring techniques (RSSI) as the inputs for the positioning estimation of sensor nodes. The traditional optimization-based localization model using PSO, BBO, FA, ABC, BA, and GA is shown in Figure 2. New smart localization model for single-based localization using the EW-CSO algorithm, as shown in Figure 3.

\section{Proposed Flow Chart}

The working principles of the proposed work are depicted as a flow chart in Figure. 4, which illustrates the flow control of a framework designed to localize mobile sensor nodes in a single beacon-based approach using computational intelligence algorithms. Computational 


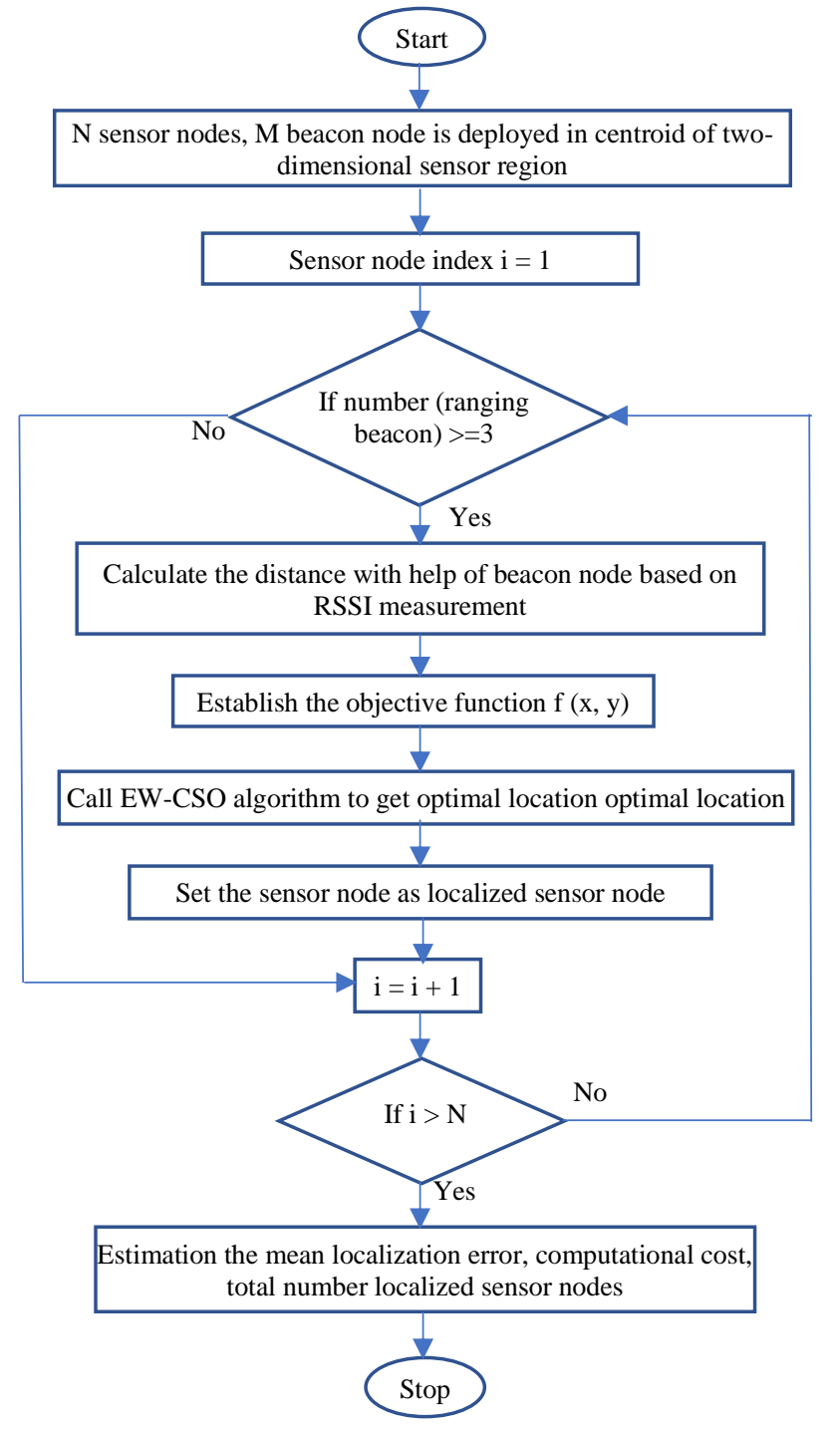

Figure 4. Flowchart of single beacon-based mobile sensor nodes localization using the EW-CSO algorithm in WSN.

intelligence algorithms are used to find optimal localization in EWO, EW-CSO, and EW-PSO algorithms.

\section{Proposed Algorithm}

The proposed algorithm is designed for single beaconbased localization using EW-CSO computational intelligence algorithms. Algorithm for EW-CSO for localization of mobile sensor nodes present below:

Inputs:

Target $t_{\text {area }}$ is a given target area where mobile sensor nodes are to deploy randomly, 1 is a length and $b$ is a breath of the target area, BN (x, y) in beacon nodes coordinate, centroid $(a, b, c, d)$ is a function to calculate the centroid of the given area and a, b, c, d are the sides of the given target area, MN $(\mathrm{x}, \mathrm{y})$ is a current location of mobile nodes, $\mathrm{SN}_{\text {total }}$ is a total number of mobile sensor nodes, dim is represent the dimensional of the target area, $i$ is denoted the index of mobile sensor nodes, $\mathrm{SN}_{\text {ref }}$ calculates the total number of beacon nodes are in their range, dist $t_{i}$ is estimating the distance between sensor nodes and beacon nodes, the position is to save the best location of optimization algorithm in each iteration, Max $_{\text {iter }}$ represents the maximum of iteration to position refinement, SearchAgent is agents are required to finding an optimal position, $\mathrm{lb}$ is a lower bound and ub is an upper bound of the given target area.

Begin:

1. Target $_{\text {area }}=1 * b$

2. $\quad B N(x, y)=$ centroid $(a, b, c, d)$

3. $\mathrm{MN}(\mathrm{x}, \mathrm{y})=$ Target $_{\text {area }} *$ rand $\left(\mathrm{SN}_{\text {total }}, \mathrm{dim}\right)$

4. for $\mathrm{i}=1$ to $\mathrm{SN}_{\text {total }}$

5. do

6. $\quad \mathrm{SN}_{\text {ref }}=\mathrm{RSSI}_{\text {recvied }}(\mathrm{BN})$

7. If $\left(\operatorname{size}\left(\mathrm{SN}_{\mathrm{ref}}\right)<=\right.$ three $\left.)\right)$

8. then

9. Distance between beacon nodes and mobile sensor node is calculated using below equation:

10. dist $_{i}=\sqrt{\left(\left(x_{t}-x\right)^{2}+\left(y_{t}-y\right)^{2}\right)}$

11. Estimate the coordinate value of SN (x, $\mathrm{y}, \mathrm{z})$ using below equations:

12. let's $\mathrm{z}=0$ for two-dimensional area

13. $\quad\left(\mathrm{x}-\mathrm{x}_{1}\right)^{2}+\left(\mathrm{y}-\mathrm{y}_{1}\right)^{2}+\left(\mathrm{z}-\mathrm{z}_{1}\right)^{2}=$ dist $_{1}{ }^{2}$

14. $\quad\left(\mathrm{x}-\mathrm{x}_{2}\right)^{2}+\left(\mathrm{y}-\mathrm{y}_{2}\right)^{2}+\left(\mathrm{z}-\mathrm{z}_{2}\right)^{2}=$ dist $_{2}{ }^{2}$

15. $\quad\left(\mathrm{x}-\mathrm{x}_{3}\right)^{2}+\left(\mathrm{y}-\mathrm{y}_{3}\right)^{2}+\left(\mathrm{z}-\mathrm{z}_{3}\right)^{2}=$ dist $_{3}{ }^{2}$

16. Call Eurasian Wolves Optimizer computational intelligence algorithm:

17. Initialize the alpha, beta, delta position using below equation

18. Positions=initialization (SearchAgents_no, dim, ub, lb)

19. while $\left(1<\right.$ Max $\left._{\text {Iter }}\right)$

20. do

21. The fitness value of alpha, beta and delta is calculated

22. Update the position of search agents

23. Call Cuckoo Optimizer for an alpha, beta, and delta

24. The final position is calculated from the below equation:

25. Position $=($ alpha + beta + delta $) / 3$;

26. End while

27. End if

28. End For

\section{Simulation Results and Analysis}

Performance analysis of the proposed EW-CSO algorithm with comparative analysis of EWO and EW-PSO algorithms in a single beacon-based localization approach. 
EWO optimization for total number of randomly deploved nodes : 200

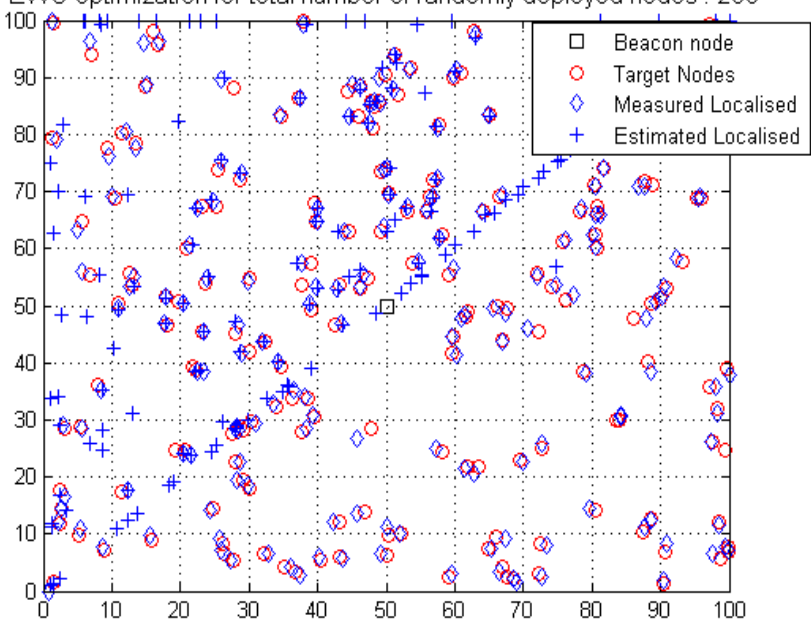

Figure 5. EWO algorithm for randomly deployed mobile sensor nodes located in the target area

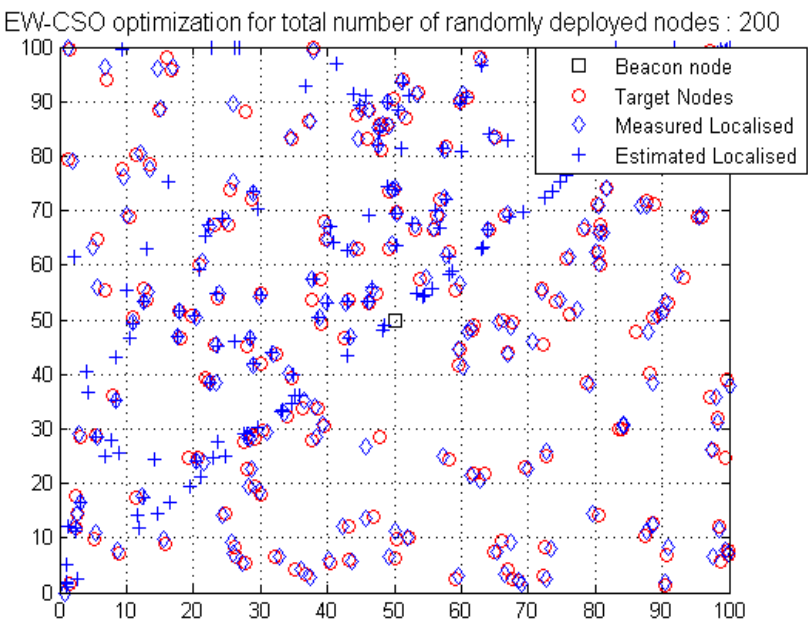

Figure 6. EW-CSO algorithm for randomly deployed mobile sensor nodes located in the target area

The performance is analyzed with the help of Matlab software on a PC with an Intel Core 17 processor, $3.40 \mathrm{GHz}$ CPU and 4 GB of RAM. This section is divided into two parts, such as the simulation scenario and performance evaluation criteria.

\section{Simulation Scenario}

In the simulation configuration, the transmission range of beacons and mobile sensor nodes is fixed at $50 \mathrm{~m}$. Random deployment of mobile sensor nodes in the target area of 100 $\mathrm{x} 100 \mathrm{~m}^{2}$. The beacon node is deployed in the center of the target area, and the free space path loss and fading model is considered. The RSSI measurement technique is used to distance estimate between mobile sensor-nodes and beacon nodes in a range-based localization approach. The optimization algorithm takes EWO, EW-CSO, and EWPSO into the simulation of a single beacon-based localization approach. In the optimization algorithm, the search agents are 10, and the maximum iteration for the estimate location refinement is set to 25 times.

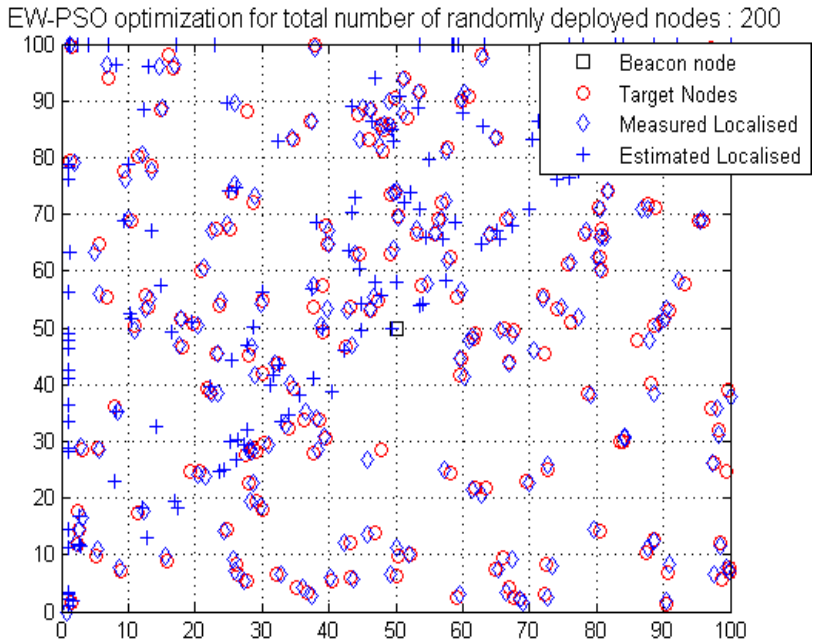

Figure 7. EW-PSO algorithm for randomly deployed mobile sensor nodes located in the target area.

\section{Performance Evaluation Criteria}

The performance evaluation criteria for a single beaconbased localization approach using the EW-CSO algorithm are mean localization error, computation cost, and number of sensors localized with the variation of the number of randomly deployed sensor nodes. In each simulation with a variation of the sensor nodes deployed from 10 to 200 with a difference of 10 . The single beacon-based localization approach, using the EWO, EW-CSO, and EWPSO algorithms, is shown in Figure 5, Figure 6, and Figure 7 for randomly deployed of 200 mobile sensor nodes.

- Mean Localization Error:

The average difference between the actual sensor node and the estimated sensor node position. Mean localization error calculation, with a difference of 10 in each simulation with a variation of mobile sensor nodes deployed from 10 to 200, as shown in Figure 8. The resulting graph shows that the EW-CSO algorithm is much better than the EWO and EW-PSO algorithms for a single beacon-based localization approach.

- Computational Cost:

The total time required to complete the process of localization for mobile sensor nodes is known as the computation cost and is typically measured in terms of seconds (seconds) unit. The computational cost of single beacon-based localization using the EW-CSO algorithm approximately lesser than compared to the EWO and EW-PSO algorithms. In each simulation, with a difference of 10 to 200 deployed mobile sensor nodes, the cost of the computation is shown in Figure 9.

- Number of Localized Nodes:

The number of sensor nodes localized on the number of randomly deployed mobile sensor nodes by a variation of 10 to 200 mobile sensor nodes with a difference of 10 to 200 sensor nodes with a difference 


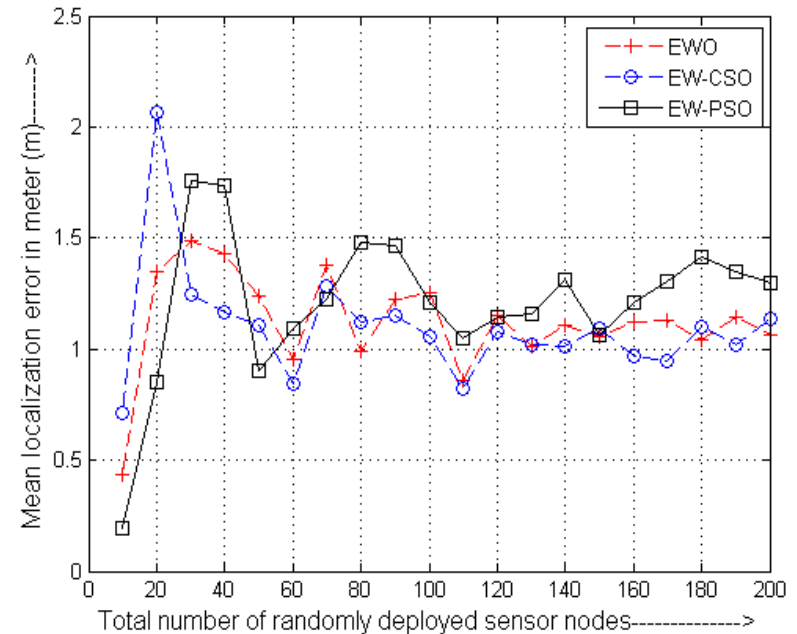

Figure 8. The mean localization error required for mobile sensor nodes localized in the target area.

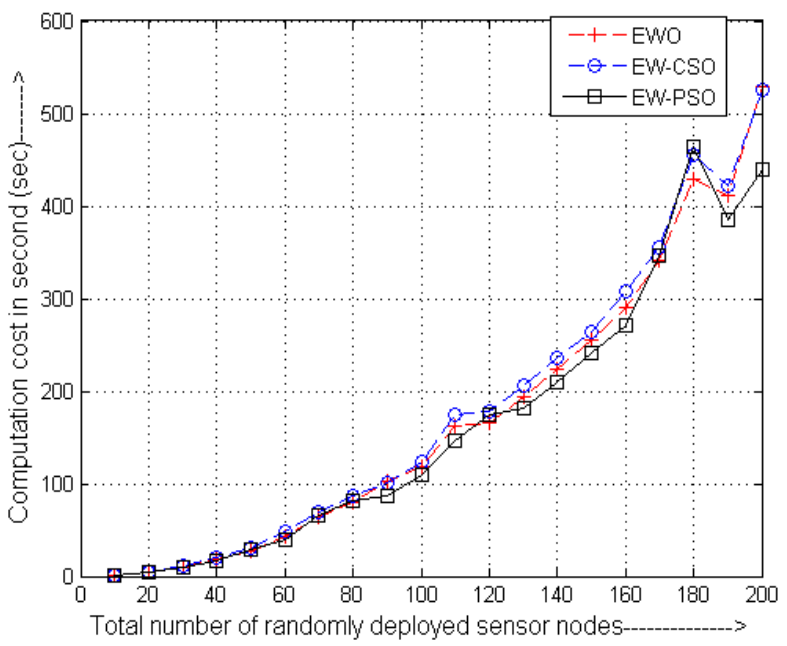

Figure 9. The total computational cost required for mobile sensor nodes localized in the target area.

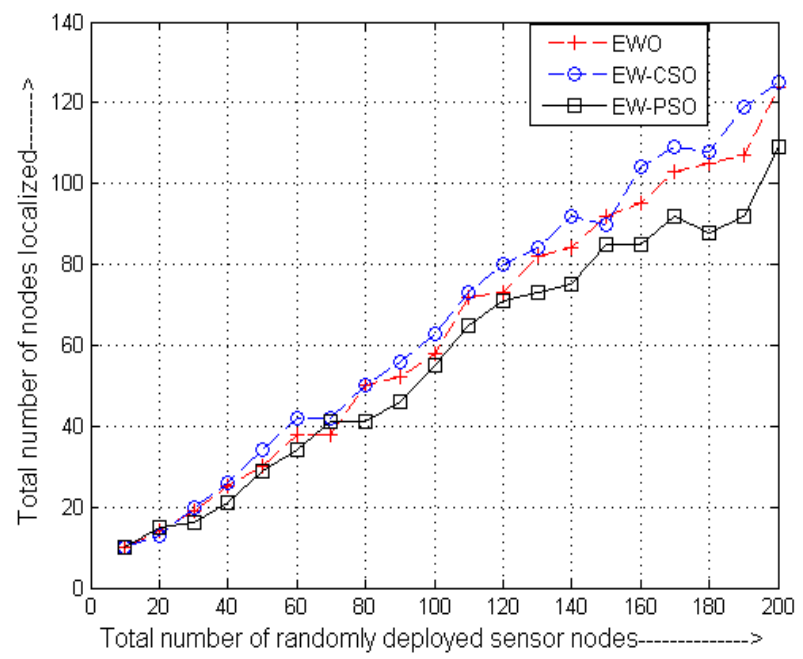

Figure 10. The total number of mobile sensor nodes localized in the target area. of 10. The number of mobile sensor nodes localized using a single beacon-based localization approach with the EWCSO algorithm is better than compared to EWO and EWPSO algorithms, as shown in Figure 10.

\section{Conclusion}

The localization of the mobile sensor node poses a significant challenge for WSN. Technology advancement leads to WSN-IoT integration to minimize human intervention. To minimize the additional cost of GPS components using a beacon-based localization approach is also minimized. The mobile sensor computes the optimal coordinate value using the EW-CSO algorithm in this paper. The simulated results and analysis of the EW-CSO algorithm are compared with the EWO and EW-PSO algorithms in a single beacon-based localization approach. The EW-CSO algorithm performs much better than the EWO and EW-PSO algorithms in terms of mean localization error, computation cost, and number of localized nodes. This approach also reduced the line of sight problem with the efficient use of hardware resources. The future direction of this proposed work can be applied to the three-dimensional target region.

\section{References}

[1] Balaji, S., Nathani, K., \& Santhakumar, R. (2019). IoT technology, applications, and challenges: a contemporary survey. Wireless personal communications, 108(1), 363388.

[2] Vikram, N., Harish, K. S., Nihaal, M. S., Umesh, R., Shetty, A., \& Kumar, A. (2017, January). A low cost home automation system using $\mathrm{Wi}-\mathrm{Fi}$ based wireless sensor network incorporating Internet of Things (IoT). In 2017 IEEE 7th International Advance Computing Conference (IACC) (pp. 174-178). IEEE.

[3] Bhatt, J. G., Jani, O. K., \& Bhatt, C. B. (2020). Automation Based Smart Environment Resource Management in Smart Building of Smart City. In Smart Environment for Smart Cities (pp. 93-107). Springer, Singapore.

[4] Sharma, R., \& Prakash, S. (2020). Enhancement of relay nodes communication approach in WSN-IoT for underground coal mine. Journal of Information and Optimization Sciences, 41(2), 521-531.

[5] Raj, A., \& Prakash, S. (2019, March). Mobile Data Gathering Approaches in Wireless Sensor Networks: A Survey. In 2019 6th International Conference on Computing for Sustainable Global Development (INDIACom) (pp. 758-762). IEEE.

[6] Bajaj, K., Sharma, B., \& Singh, R. (2020). Integration of WSN with IoT Applications: A Vision, Architecture, and Future Challenges. In Integration of WSN and IoT for Smart Cities (pp. 79-102). Springer, Cham.

[7] Kaur, A., Gupta, G. P., \& Mittal, S. (2020). Impact of Nature-Inspired Algorithms on Localization Algorithms in Wireless Sensor Networks. In Nature-Inspired Computing Applications in Advanced Communication Networks (pp. 1-18). IGI Global.

[8] Sharma, R., \& Prakash, S. (2019, March). Latest Trends and Future Directions of Localization Algorithms in Wireless 
Sensor Networks. In 2019 6th International Conference on Computing for Sustainable Global Development (INDIACom) (pp. 626-631). IEEE.

[9] Sharma, R., \& Prakash, S. (2018, October). Emerging Trends in Localization Techniques for WSNs: A Review. In 2018 International Conference on Advances in Computing, Communication Control and Networking (ICACCCN) (pp. 1119-1124). IEEE.

[10] Dil, B., Dulman, S., \& Havinga, P. (2006, February). Rangebased localization in mobile sensor networks. In European Workshop on Wireless Sensor Networks (pp. 164-179). Springer, Berlin, Heidelberg.

[11] Stoleru, R., He, T., \& Stankovic, J. A. (2007). Range-free localization. In Secure Localization and Time Synchronization for Wireless Sensor and Ad Hoc Networks (pp. 3-31). Springer, Boston, MA.

[12] Adewumi, O. G., Djouani, K., \& Kurien, A. M. (2013, February). RSSI based indoor and outdoor distance estimation for localization in WSN. In 2013 IEEE international conference on Industrial technology (ICIT) (pp. 1534-1539). IEEE.

[13] Ravindra, S., \& Jagadeesha, S. N. (2014). Time of arrival based localization in wireless sensor networks: A linear approach. arXiv preprint arXiv:1403.6697.

[14] Rong, P., \& Sichitiu, M. L. (2006, September). Angle of arrival localization for wireless sensor networks. In 2006 3rd annual IEEE communications society on sensor and ad hoc communications and networks (Vol. 1, pp. 374-382). Ieee.

[15] Xiong, H., Chen, Z., Yang, B., \& Ni, R. (2015). TDOA localization algorithm with compensation of clock offset for wireless sensor networks. China Communications, 12(10), 193-201.

[16] Xiao, H., Zhang, H., Wang, Z., \& Gulliver, T. A. (2017, August). An RSSI based DV-hop algorithm for wireless sensor networks. In 2017 IEEE Pacific Rim Conference on Communications, Computers and Signal Processing (PACRIM) (pp. 1-6). IEEE.

[17] Blumenthal, J., Reichenbach, F., \& Timmermann, D. (2005, March). Position estimation in ad hoc wireless sensor networks with low complexity. In Joint 2nd workshop on positioning, navigation and communication (pp. 41-49).

[18] Zhou, Z. D., Hu, P., Liu, Q., \& Li, F. M. (2007). MDS-based fast localization algorithm for wireless sensor networks. Chinese Journal of Sensors and Actuators, 20(10), 23032307.

[19] Albowicz, J., Chen, A., \& Zhang, L. (2001, November). Recursive position estimation in sensor networks. In Proceedings Ninth International Conference on Network Protocols. ICNP 2001 (pp. 35-41). IEEE.

[20] De Oliveira, H. A. B. F., Boukerche, A., Nakamura, E. F., \& Loureiro, A. A. F. (2008). An efficient directed localization recursion protocol for wireless sensor networks. IEEE Transactions on Computers, 58(5), 677-691.

[21] Tavakolpour, V., Malazi, H. T., \& Eshghi, F. (2017). Bilateral localisation algorithm for wireless sensor networks with communication holes. IJSNet, 23(2), 73-86.

[22] Singh, P., Khosla, A., Kumar, A., \& Khosla, M. (2018). Computational intelligence-based localization of moving target nodes using single anchor node in wireless sensor networks. Telecommunication Systems, 69(3), 397-411.

[23] Iram, R., Sheikh, M. I., Jabbar, S., \& Minhas, A. A. (2011, July). Computational intelligence based optimization in wireless sensor network. In 2011 International Conference on Information and Communication Technologies (pp. 1-6). IEEE.
[24] Mirjalili, S., Mirjalili, S. M., \& Lewis, A. (2014). Grey wolf optimizer. Advances in engineering software, 69, 46-61.

[25] Yang, X. S., \& Deb, S. (2009, December). Cuckoo search via Lévy flights. In 2009 World congress on nature \& biologically inspired computing (NaBIC) (pp. 210-214). IEEE.

[26] Kennedy, J., \& Eberhart, R. (1995, November). Particle swarm optimization. In Proceedings of ICNN'95International Conference on Neural Networks (Vol. 4, pp. 1942-1948). IEEE

[27] Singh, P., Khosla, A., Kumar, A., \& Khosla, M. (2017). 3D localization of moving target nodes using single anchor node in anisotropic wireless sensor networks. AEUInternational Journal of Electronics and Communications, 82, 543-552.

[28] Singh, P., Khosla, A., Kumar, A., \& Khosla, M. (2018). Optimized localization of target nodes using single mobile anchor node in wireless sensor network. AEU-International Journal of Electronics and Communications, 91, 55-65.

[29] Kaur, A., Kumar, P., \& Gupta, G. P. (2019). A new localization using single mobile anchor and mesh-based path planning models. Wireless Networks, 25(5), 29192929.

[30] Parulpreet, S., Arun, K., Anil, K., \& Mamta, K. (2019). Computational Intelligence Techniques for Localization in Static and Dynamic Wireless Sensor Networks-A Review. In Computational Intelligence in Sensor Networks (pp. 2554). Springer, Berlin, Heidelberg.

[31] Tuba, E., Tuba, M., \& Beko, M. (2018). Two stage wireless sensor node localization using firefly algorithm. In Smart trends in systems, security and sustainability (pp. 113-120). Springer, Singapore.

[32] Strumberger, I., Tuba, E., Bacanin, N., Beko, M., \& Tuba, M. (2018, April). Monarch butterfly optimization algorithm for localization in wireless sensor networks. In 2018 28th International Conference Radioelektronika (RADIOELEKTRONIKA) (pp. 1-6). IEEE.

[33] Alomari, A., Phillips, W., Aslam, N., \& Comeau, F. (2018). Swarm intelligence optimization techniques for obstacleavoidance mobility-assisted localization in wireless sensor networks. IEEE Access, 6, 22368-22385.

[34] Strumberger, I., Beko, M., Tuba, M., Minovic, M., \& Bacanin, N. (2018, May). Elephant herding optimization algorithm for wireless sensor network localization problem. In Doctoral Conference on Computing, Electrical and Industrial Systems (pp. 175-184). Springer, Cham.

[35] Rajakumar, R., Amudhavel, J., Dhavachelvan, P., \& Vengattaraman, T. (2017). GWO-LPWSN: Grey wolf optimization algorithm for node localization problem in wireless sensor networks. Journal of Computer Networks and Communications, 2017

[36] Strumberger, I., Minovic, M., Tuba, M., \& Bacanin, N. (2019). Performance of Elephant Herding Optimization and Tree Growth Algorithm Adapted for Node Localization in Wireless Sensor Networks. Sensors, 19(11), 2515.

[37] Tan, R., Li, Y., Shao, Y., \& Si, W. (2019). Distance Mapping Algorithm for Sensor Node Localization in WSNs. International Journal of Wireless Information Networks, 110.

[38] Ahmad, T., Li, X. J., \& Seet, B. C. (2017). Parametric loop division for 3D localization in wireless sensor networks. Sensors, 17(7), 1697. 